\title{
Incidencia de la potestad del procurador para dar muerte política a un funcionario electo por voto popular*
}

\author{
Christian Camilo Suárez Ramirez**
}

Recepción: 8 de julio de 2017 Aprobación: 29 de septiembre de 2017

\section{RESUMEN}

Con la presente investigación se busca evidenciar con claridad la relación y nivel de prioridad respecto de las funciones asignadas al procurador contra la importancia del derecho al voto y su efectividad democrática en un Estado social de derecho que necesita con urgencia reglamentar las actuaciones del Ministerio Público de acuerdo con los derechos y garantías constitucionales y convencionales que tiene un funcionario electo por voto popular.

Ahora bien, por medio de una metodología básica cualitativa esperamos poder identificar con claridad las etapas y formas de desarrollar por parte de la Procuraduría el proceso disciplinario especial encaminado a sancionar posibles hechos disciplinables, y poder vislumbrar si se realiza la debida aplicación de las normas, tratados y conceptos de la Corte Interamericana de Derechos Humanos respecto de la materia.

Todo lo anterior para poder llegar a establecer que se requiere la reglamentación positiva del procedimiento especial sancionatorio que se aplica por parte del procurador contra servidores electos por sufragio, así como implementar garantías políticas tanto para el investigado como

* El artículo es producto del proyecto de investigación "La incidencia de la potestad del procurador para dar muerte política a un funcionario electo por voto popular" gestionado en el marco del programa de la Especialización en Derecho Administrativo de la Universidad Libre, Bogotá, Colombia. DOI: http://dx.doi.org/10.15332/ s1909-0528.2018.0001.05

** Abogado y especialista en Derecho Administrativo de la Universidad Libre. Bogotá - Colombia. Abogado Sénior en Asesorías C\&J y asesor en temas de contratación estatal. suarezramirezderecho@gmail.com 
para sus electores y finalmente que se ajuste el procedimiento por medio del acompańamiento de la rama judicial.

Palabras clave: bloque de constitucionalidad, Estado social, derechos políticos, garantías constitucionales, garantías convencionales.

\section{Abstract}

This research seeks to clearly show the relationship and level of priority regarding the functions assigned to the Attorney against the importance of the right to vote and its democratic effectiveness in a social state of law that urgently needs to regulate the actions of the Public Prosecutor's Office According to the constitutional and conventional rights and guarantees of an elected official by popular vote.

However, through a qualitative basic methodology, we hope to be able to clearly identify the stages and ways of developing by the Office of the Attorney General the special disciplinary process aimed at sanctioning possible disciplinary facts, and to be able to see if the proper application of norms, treaties and concepts of the Inter-American Court of Human Rights with respect to the matter.

All of the above in order to establish that the positive regulation of the special sanctioning procedure that is applied by the Attorney against elected officials by suffrage is required, as well as to implement political guarantees for both the investigated and the voters, and finally, the procedure through the accompaniment of the judicial branch.

Keyswords: constitutional block, Social State, political rights, constitutional guarantees, conventional guarantees. 


\section{INTRODUCCIÓN}

A través del siguiente texto científico hemos querido dar respuesta al siguiente interrogante: ¿cuál es la incidencia de la potestad del procurador para dar muerte política a un funcionario electo por voto popular? ¿Qué incidencia tendrá en la seguridad democrática del país el hecho de que las garantías constitucionales y convencionales ratificadas por Colombia no sean tenidas en cuenta a la hora de tomar determinaciones de este tipo?

Se utilizará una metodología de investigación básica cualitativa por medio de la cual esperamos demostrar la incidencia de las decisiones que van en contravía de la expresión democrática de una mayoría de ciudadanos para poder discernir que no hay claridad en la reglamentación de las funciones, facultades y medios de controversia de las disposiciones adoptadas por el procurador y que pueden llegar a suplantar la calidad de juez. Para obtener tal fin se utilizarán fuentes primarias y secundarias.

De la misma forma, por medio de una investigación explicativa esperamos poder establecer que no hay garantías políticas para aquellos funcionarios que fuesen investigados por esta corporación. Así las cosas, la única manera de hacerle ver al Congreso de la República la insistente y urgente necesidad de reglamentar positivamente los límites y controles a las facultades establecidas en la Constitución Política del 91 en sus artículos 275 al 284 y en el Código Único Disciplinario (Ley 734 del 2002), es que se logre concluir que dichas disposiciones han transgredido el ordenamiento internacional afectando así el bloque de constitucionalidad y dejando en entredicho la estabilidad político-democrática del país.

Ahora bien, dando continuidad al problema jurídico de investigación en estudio tendremos que empezar a buscar opciones viables para que aquellos funcionarios que sean elegidos en sus cargos por el sufragio de los ciudadanos tengan también un control disciplinario, administrativo y político, toda vez que su elección no es una figura autoritaria ni mucho menos todopoderosa. Es estrictamente necesario que a este respecto se refleje la necesidad de que el Congreso expida ya sea una ley específica sobre dicha situación o acople y ajuste en debida forma las ya existentes. 


\section{RELACIÓN Y NIVEL DE PRIORIDAD RESPECTO DE LAS FUNCIONES ASIGNADAS AL PROCURADOR GENERAL DE LA NACIÓN CONTRA LA IMPORTANCIA DEL DERECHO AL VOTO Y SU EFECTIVIDAD DEMOCRÁTICA EN UN ESTADO SOCIAL DE DERECHO}

Al Estado le corresponde salvaguardar la seguridad interior y exterior del país. Estamos, pues, ante una actividad de cometido exclusivamente público-estatal (Nieves, 2016). En este orden de ideas, prevé el numeral 6 del art. 277 de la Constitución Política de Colombia que la Procuraduría General de la Nación debe "ejercer vigilancia superior sobre la conducta oficial de quienes desempeñen funciones públicas, inclusive las de elección popular”. Así las cosas, constitucionalmente esta corporación tanto como su supremo director tienen la facultad autónoma de iniciar procesos disciplinarios y de resolverlos sin que se evidencie que dicha potestad tenga límites, garantías y donde sí interfiere e incluso se suplanta la vía judicial, que es la única posibilidad válida según los lineamientos de la Corte Interamericana de Derechos Humanos para dar muerte política a funcionario electo por voto popular.

Así las cosas, es indispensable que el Congreso de la República parametrice y reglamente en forma clara - y atendiendo a los principios rectores que fundamentan la Convención Interamericana de Derechos Humanos - las potestades y funciones de índole disciplinario que tiene la tan mencionada corporación, para que nunca más decisiones administrativas y no judiciales entren a afectar los derechos políticos de millones de ciudadanos que votaron por un funcionario para luego verlo destituido (Constitución Política, 2015).

Podremos, entonces, empezar a concluir con cierto grado de certeza que la capacidad otorgada al procurador va en contravía del art. 40 de nuestra Carta Política, que en su numeral primero expresa que es un derecho político de todo ciudadano la elección de presidente, vicepresidente y alcalde, entre otros. En este sentido, nos encontraremos frente a una violación flagrante de dichos presupuestos civiles y políticos si una decisión sin la debida revisión y contradicción da fin al resultado (elección popular) de la plusvalía democrática

La Procuraduría es el máximo garante de los derechos civiles y colectivos y si esta misma genera la inestabilidad democrática al tomar a la ligera la importante decisión 
de sancionar e inhabilitar a un funcionario público sin que medie la decisión de un juez, estamos frente un enorme inconveniente que debe ser resuelto para no causar daños irreparables.

Lo anterior ya que si un funcionario que es electo por el Senado, por una terna integrada por candidatos postulados por la Corte Suprema, el Consejo de Estado y el presidente, tiene la posibilidad legal de controvertir la decisión tomada por una mayoría significativa de ciudadanos, ¿̇ónde queda entonces la seguridad política y democrática del Estado? Más aún en un Estado social democrático y participativo de derecho como lo es Colombia.

Y si las decisiones que adopte dicho funcionario no están acorde a los tratados ratificados o son violatorios de derechos políticos - porque en un principio le fueron asignadas dichas calidades-, no se previó un desbordamiento de poder, no se tuvo en cuenta la base sobre la que se fundamentó nuestra organización estatal, la cual, como se mencionará con mayor detalle, basa su existencia en la división de poderes para así impedir los monopolios y poder ejercer control y contradicción de las decisiones de índole política, económica, social y ambiental.

Ahora, si precisamente la división de poderes se gestó con la intención de que se realizara control y hubiese barreras en la conducción del poder político y entendiendo como ya está claro que la Procuraduría General de la Nación es el máximo ente disciplinario y que el procurador general del Nación es la más alta autoridad disciplinaria, no es conveniente que las decisiones por él adoptadas tengan por lo menos la posibilidad de ser revisadas, ya sea por la Honorable Corte Constitucional, si se quiere dar una verdadera garantía constitucional a estas decisiones.

Si pensamos de esta forma no estamos dejando de lado la primicia del poder preferente de la Procuraduría General de la Nación, ni mucho menos poniendo en tela de juicio su total control sobre esta rama del derecho, ya que como se verá más adelante su potestad primaria de decisión es absoluta y el resto de entidades públicas lo reconocen y atienden; solo estamos analizando el hecho de que a mayor nivel de afectación por una decisión, mayor debería ser su control y sus etapas de contradicción. 
Así pues, si con la decisión se destituye a un funcionario, servidor público de carrera o a un contratista, dicha decisión que tiene el recurso de reposición y en subsidio de apelación afectará al involucrado y a su núcleo familiar. Pero si esta decisión recae en un servidor público electo por voto popular esta decisión afectará no solo al investigado y su núcleo familiar, sino también a las familias de su equipo de trabajo y principalmente a todos los ciudadanos que votaron por dicho servidor.

Ahora bien, no se puede desconocer las funciones tan importantes que tiene a su cargo la Procuraduría General de la Nación ni mucho menos de su más eminente representante y máxima autoridad disciplinaria, ya que en ellos recae la obligación de salvaguardar la ética, la moral y honra en las actuaciones de funcionarios públicos, así como llevar acabo en caso necesario el seguimiento de aquellas quejas ante servidores públicos en razón a su arbitrario, ilegal o ineficiente proceder. De la misma forma, dichos órganos estatales deben velar por el cabal cumplimiento de la Carta Política del 91 en todas y cada una de sus actuaciones, desplegadas en cumplimiento de la función administrativa (Bitro, 2006).

Tan solo hay que ver la misionalidad de la Procuraduría, su extensión y dimensiones para comprobar de primera mano la importancia de su correcto y coherente funcionamiento, así como la necesidad de nuevas directrices en la ejecución de los procesos sancionatorios, con miras a llenar de garantías políticas y civiles a los investigados y principalmente para que el procurador limite sus actuaciones al marco sobre el cual tiene disposición y no trasgreda su capacidad generando decisiones que debiesen ser de única tutela de un juez de la República (Procuraduría General de la Nación, 2017).

De esta forma, llegamos al epicentro de esta primera parte de la investigación, enfrentando la seguridad jurídico-democrática de los ciudadanos al momento de ratificar el respeto a las decisiones por estos adoptadas contra la capacidad de autopotestad y control del organismo bajo estudio. Al respecto, no encontramos que una sea superior a la otra jerárquicamente. Lo que sí se evidenció es que las funciones exacerbadas sin límites y garantías que tiene actualmente el procurador al momento de emitir decisiones de destitución e inhabilidad política contra funcionarios electos por voto popular violenta dicha seguridad y deja en tela de juicio la forma como el Estado y sus representantes dan más prioridad al control político-disciplinario con visos opre- 
sivos que al garantismo que caracteriza a un Estado social democrático y participativo de derecho.

Siguiendo la estructura de la explicación y de conformidad con el ámbito interno, nos encontramos doctrinalmente con un problema que es de viaja usanza, ya que la concentración del poder es un impedimento antiguo que no permite que los Estados ejerzan prácticas democráticas ajustadas a un Estado social, democrático y participativo de derecho que brinde garantías reales y que eviten el abuso del poder. $\mathrm{Al}$ respecto, resulta procedente reflexionar sobre
si el modelo de la democracia representativa que perdura hasta nuestros días realmente es coherente con el ethos que suele atribuírsele a la democracia como sistema político en la actualidad o si, por el contrario, el modelo representativo supone rupturas o costos al sistema democrático. (Gómez, 2016, p. 159)

Este entonces podría ser precisamente el problema de la falta de control y la concentración del poder en una sola institución, dejando de lado la armonía que la administración pública debe tener con el resto de organismos y llevando a cabo procedimientos administrativos de índole sancionatorios sin contar con la rama judicial y su acompańamiento.

Finalmente tendremos que recalcar el hecho de que la legislación interna no posee un mecanismo expedito, sólido y efectivo que le permita al funcionario público que se ve perjudicado por una decisión de esta índole asegurar el goce de sus derechos políticos y el de todas aquellas personas que apoyaron su plan de gobierno o sus proyectos de políticas públicas en la forma del sufragio.

\section{DERECHOS Y GARANTÍAS CONSTITUCIONALES Y CONVENCIONALES QUE TIENE UN FUNCIONARIO ELECTO POR VOTO POPULAR}

De conformidad con Romero, aunque sea reiteración doctrinaria, jurisprudencial y normativa, deben respetarse los derechos humanos en cualquier tipo de proceso judicial (Romero, 2017); es por ello que los derechos civiles y políticos han sido ratificados innumerables veces a través de la historia y no forma parte de este estudio 
el hacer un repaso de la historia de este tipo de derechos; el interés de este artículo se concentra más en analizar la evolución de los derechos políticos y ahondar puntualmente en las garantías que el ordenamiento nacional - y por medio del bloque de constitucionalidad de los acuerdos, tratados y pactos - haya reconocido, ratificado y que le dan a un funcionario público electo por voto popular.

En este orden de ideas, lo primero que cabe mencionar es entonces el desarrollo constitucional de la función pública y del derecho al voto, ya que el desarrollo normativo internacional es ostensible. La Constitución Política reconoce en su art. 40 el derecho que tiene todo ciudadano a elegir y ser elegido así como a hacer parte de la conformación, ejercicio y control del poder político (Constitución Política, 2105). Esto a pesar del hecho de que la democracia se ha convertido en un espejismo, donde los intereses de los gobernados no se ven representados puesto que no pertenecen a la red de poder que está facultada para apropiarse del sistema político, económico y burocrático (Rodríguez, 2017).

Igualmente, el art. 123 de la Carta Magna indica que los servidores públicos serán todas aquellas personas que trabajen en organismos estatales independientemente de si son entidades del orden central o descentralizado, así como el siguiente art. establece que la ley determinará la forma de ejercer y el tipo de responsabilidad de los servidores públicos, y el subsiguiente indica que todos los servidores públicos serán de carrera administrativa excepto los de libre nombramiento y remoción así como los de elección popular y los demás que determine la ley (Constitución Política, 2015).

Ahora bien, dentro del sumario de derechos que tienen la capacidad de obligar al Estado a protegerlos de forma inmediata están los del art. 85 de la Constitución y entre estos hallaremos los derechos políticos, piedra angular de esta parte del estudio, igualmente ratificados por nuestro ordenamiento mediante la Ley 16 de 1972 que trae consigo la Convención Americana de Derechos Humanos, también llamado pacto de San José, y este en su art. 23 habla de los derechos políticos (Corte Suprema de Justicia, 2014).

En este orden de ideas, la Corte Suprema de Justicia por medio de la Sentencia 791 de 2014 esgrimió el alcance de los derechos políticos y a su tenor dijo: 
los derechos políticos son derechos humanos de importancia fundamental dentro del sistema interamericano que se relacionan estrechamente con otros derechos consagrados en la Convención Americana como la libertad de expresión, la libertad de reunión y la libertad de asociación y que, en conjunto, hacen posible el juego democrático. (Corte Suprema de Justicia, 2014, p. 15)

De la misma forma, la CADH prohíbe la suspensión de los derechos políticos por otorgarles una importancia fundamental en el normal desarrollo político de un país. Dicha prohibición está taxativa en el artículo 27 de la mencionada convención.

También cabe hacer referencia al importante espacio que tienen las garantías para que los derechos políticos de un servidor público electo popularmente en nuestro país se respeten. A este respecto, vale la pena señalar que dentro de la legislación interna no habrá un recurso jurídico o un mecanismo legal que le permita al investigado hacer valer dichos derechos, solo es posible hacerlo por medio de un instrumento fundamental, como lo es el bloque de constitucionalidad, el cual es definido por la Honorable Corte Constitucional en la Sentencia C-067 de 2003 como la "unidad jurídica compuesta por normas y principios que, sin aparecer formalmente en el articulado del texto constitucional, son utilizados como parámetros del control de constitucionalidad de las leyes" (Corte Constitucional, 2003).

Dicho lo anterior, es posible entrever cómo los tratados de derechos políticos ratificados por Colombia le dan un instrumento garantista de una naturaleza cautelar a fin de que decisiones tomadas sin el respeto al debido proceso cesen sus efectos antes de generar daños irreversibles; para el caso en mención, aquel funcionario público que sienta que se está atentando contra sus derechos políticos podrá solicitar el amparo de una media cautelar, ya sea esta dictada por la CIDH o por la CADH.

Y no solo podrá acudir a este tipo de mecanismo aquel servidor público que se vea inmerso en un proceso disciplinario por parte de la Procuraduría en el cual se dé como resultado una decisión negativa que afecte sus derechos políticos, sino que también podrá acceder a dicho mecanismo aquel ciudadano que se vea afectado indirectamente con la destitución e inhabilidad de dicho servidor público, ya que su derecho a elegir se ve fracturado por la decisión del ente de control, de ahí que también este particular pueda solicitar la protección de sus derechos. 
Lo que debe observarse con atención es el preocupante hecho de que para que se garanticen derechos políticos fundamentales, para que haya el adecuado control en las decisiones de destitución e inhabilidad — como resultado de un proceso disciplinario que no tiene la calidades, tiempos, garantías, espacios y recursos que caracteriza el proceso ordinario_-, se tiene que recurrir a un mecanismo de derecho internacional.

Esta situación es algo realmente grave. Su trascendencia e incidencia tiene un alcance mucho más amplio del que puede llegar a entenderse a primera vista y su espectro de afectación incluye tanto a los servidores públicos afectados con la decisión como a una inmensa mayoría que asistió a las urnas para hacer valer su derecho fundamental al sufragio.

Si se miran todos estos hechos fácilmente verificables — pues basta con revisar las normas constitucionales y las leyes que sustenten la materia-, se logra entender que en la legislación interna no hay un recurso legal de aplicación inmediata, ya que contra la decisión del procurador solo procede el recurso de reposición que él mismo resolverá, lo cual se explicará a fondo más adelante. Allí se agota la vía gubernativa, ahora habrá que recurrir a la jurisdicción contenciosa administrativa, ya que toda decisión de la administración pública podrá demandarse ante esta jurisdicción; la pregunta es, entonces, cuánto tiempo habrá de esperar el funcionario y sus votantes antes de que dicha sentencia profiera una respuesta de fondo.

Empezamos a ver la profundidad y la gravedad de la situación, si pensamos que el alcalde o gobernador destituido por el procurador es apartado de su cargo sin que medie una sentencia judicial. En este sentido, atendiendo a la normativa interna, el funcionario destituido interpondrá contra la decisión desfavorable el recurso de reposición, justificando que la decisión adoptada no cumple los requisitos mismos de protección, alegando que sus derechos políticos sean respetados. Sin embargo, como el recurso será resuelto por el mismo procurador — quien está seguro en su error, irrespetando así los parámetros de la Corte Interamericana de Derechos Humanos_- él mismo confirmará la destitución e inhabilidad, y como este es el único recurso dicha decisión quedará en firme.

Ahora bien, el alcalde, gobernador o funcionario público electo por voto popular afectado no tendrá otra garantía legal interna, pero sí podrá acudir a la protección 
internacional del pacto ratificado por Colombia ante la Corte Interamericana de Derechos Humanos. Este ente prevé una especial protección con garantías políticas muy taxativas, para poder destituir a este tipo de servidores públicos, así que al darse cuenta de que el ente de control y su director — sin ostentar la calidad de juez de la República y sin seguir un adecuado y garantista proceso sancionatorio- decidió apartarlo del cargo, ordenará que sea reincorporado mientras se decide de fondo un caso como del ejemplo mencionado.

Mientras esto sucede, habrá pasado una cantidad de tiempo considerable, sobre todo si se piensa en la magnitud de la agenda política de un servidor público como este, quien deberá esperar que internamente se adopte la protección de la medida cautelar dictada y que se respeten los derechos políticos, y durante ese lapso habrá transcurrido otra cantidad de tiempo considerable en la cual todos los planes, proyectos, inversiones, compras y reuniones sufrirán una seria afectación, y a su vez el normal desarrollo de la ciudad, municipio o población.

\section{ETAPas Y Forma de Desarrollar por ParTe de la Procuraduría GENERAL DE LA NACIÓN loS PROCESOS DISCIPLINARIOS ENCAMINADOS A SANCIONAR POSIBLES HECHOS DISCIPLINABLES}

Este será un estudio un poco más prolongado que los anteriores debido a la extensión del procedimiento disciplinario que tiene a su cargo dicho ministerio público y a sus múltiples etapas. Desde la citada perspectiva, empezaremos por identificar las diferencias principales entre el procedimiento disciplinario que ejerce cualquier entidad estatal y el que realiza la Procuraduría General de la Nación y su director.

Lo primero que cabe señalar será la potestad preferente que tiene la Procuraduría General frente a los órganos de control interno, ya que en cualquier momento o etapa puede el Ministerio solicitar que se le sea enviado el expediente para continuar con la investigación (Bitro, 2006).

A diferencia del Consejo Superior de la Judicatura, quien tiene dicha preferencia para con los procesos que recaigan en los funcionarios de la Rama Judicial, ninguna entidad podrá oponerse a dicha solicitud en ningún caso. Igualmente, si el investiga- 
do lo desea podrá solicitar que su proceso sea llevado por parte de la Procuraduría, pero será esta entidad quien determine si se llevará o no.

Es una gran ironía a este punto y con todo lo estudiando que la doctrina mencione que, según resolución No. 346 de 2002 art. 6 expedida por la Procuraduría General, para ejercer el control preferente es uno de los motivos el que no se tenga la certeza de obtener las garantías suficientes (Procuraduría General de la Nación, 2002).

El art. 191 del Código Único Disciplinario indica que cualquier vacío en el procedimiento especial que lleva a cabo el procurador General de la Nación —y que es objeto de análisis del presente artículo — se resolverá por medio del proceso disciplinario ordinario, motivo por el cual será necesario explicar en forma sucinta este procedimiento para así poder tener claridad a la hora de entender el procedimiento especial (Código Único Disciplinario, 2002).

En primer lugar, el procedimiento ordinario podrá iniciarse por queja, informe de entidad, información en medios o de oficio y concluirá con la decisión luego de analizar el expediente, la queja o el material a que haya lugar, si se debe iniciar la investigación o si por el contrario se archivará.

No se tiene un requisito previo para poder interponerla ni se solicitan formalismos adicionales a presentar un escrito o elevarla verbalmente para que de oficio se proceda con la verificación de los hechos que puedan considerarse presuntamente como faltas. Ahora bien, si se tiene la suficiente certeza respecto de la conducta inapropiada por cualquiera de los medios antes escritos, se iniciará el proceso de investigación.

Si tal certeza es suficiente el investigador solicitará entonces que se dicte un auto que contenga los hechos y la identificación del investigado (si se tiene). Allí mismo se podrán solicitar y aportar pruebas con el objeto de tener la mayor certeza sobre el asunto a investigar; de la misma forma y dando aplicación a los postulados base del procedimiento disciplinario, como son el debido proceso, la defensa, la contradicción, etc. (Brito, 2006).

Es fundamental y todos los doctrinantes hacen énfasis en la importancia de que la notificación se haga de la manera correcta y de forma inmediata a como se tenga la 
certeza e individualización del investigado, para que así no se violen derechos fundamentales ni se dé lugar a la declaratoria de nulidad de la investigación (Brito, 2006).

Ahora bien, será necesario profundizar en el procedimiento específico que tiene a su cargo la Procuraduría, para detallar las diferencias y la especialidad con el resto de procedimientos disciplinarios desarrollados por los organismos de control interno de las diferentes entidades públicas. Un claro ejemplo de ello es que las Procuradurías Provinciales podrán adelantar las investigaciones que sean de resorte de las Procuradurías Delegadas, esto hasta antes de que se inicie la indagación preliminar, momento en el cual se entregará el expediente con las actuaciones adelantadas al funcionario competente para que este prosiga y decida (Brito, 2006).

Lo dispuesto anteriormente es importante, porque permite ver cómo la Procuraduría tiene la tutela de los procedimientos disciplinarios y por tanto es el garante de que se desarrollen con respeto a los valores constitucionales y supralegales, y con el objetivo de ese cumplimiento, se le permite a las Procuradurías Provinciales adelantar todas las actuaciones que considere necesarias con el fin de establecer las condiciones de tiempo, modo y lugar de las presuntas faltas disciplinarias sin que por ello se pueda alegar algún tipo de nulidad (Brito, 2006).

Ahora bien, si el investigador considera que se cumple con los requisitos para continuar se ordenará el auto de pliego de cargos, en caso contrario se expedirá auto para continuar con la etapa de investigación y poder establecer con certeza las circunstancias que rodean los presuntos hechos disciplinables (Código Disciplinario Único, 2002).

El término de la investigación podrá ser de seis meses y prorrogable hasta tres más. Es importante enfatizar que las etapas descritas son de aplicabilidad obligatoria y de no darse su estricto cumplimiento podría derivar en una nulidad. Si bien aún no se ha entrado a analizar en este artículo los procedimientos disciplinarios que son de potestad exclusiva del procurador y sobre los cuales radica el mayor interés de este estudio, no puede dejarse de lado el proceso ordinario que es la base de esta rama sancionatoria del derecho (Brito, 2006). 
Al finalizar la etapa de investigación se tomará la decisión de si se archiva el proceso o, por el contrario, si se ha reunido la suficiente certeza, se inicia la etapa esencial del proceso ordinario como lo es el pliego de cargos (Código Disciplinario Único, 2002).

El pliego de cargos es el documento con el que se formaliza la acusación. Los diferentes autores, tratadistas, jurisconsultos y letrados en la materia así como la Ley 734 de 2002 —norma por excelencia que rige en materia disciplinara de servidores públicos - dicen que debe contener como mínimo la descripción de tiempo, modo y lugar de realización de la conducta, las normas violadas, la individualización del investigado tanto como el cargo que desempeńa y de igual forma la valoración de las pruebas así como las características de menor o mayor gravedad, la forma de culpabilidad y un análisis de los argumentos expuestos por el investigado (Código Disciplinario Único, 2002).

Luego de que se presente el pliego de cargos y en el mismo auto donde se soliciten y decreten pruebas se indicará a las partes la fecha y hora de realización del acervo probatorio, con el fin de que estos ejerzan su derecho a la defensa y a la contracción. Después de que se tengan todas las pruebas se les permitirá a las partes y sus apoderados que presenten sus alegatos de conclusión para dar un conocimiento general del proceso y de sus argumentos más importantes. De no presentase los alegatos, el expediente ingresara al despacho y en un término no mayor a veinte días se deberá dar el fallo disciplinario.

Este fallo deberá indicar si se exonera al investigado o si, por el contrario, se le encuentra culpable y admitirá el recurso de apelación el cual deberá tener el suficiente sustento. No se podrán solicitar pruebas, sino oficio, y este deberá versar sobre los temas en discusión en la primera instancia (Brito, 2006).

El procedimiento especial que tiene el procurador general de la Nación se da por mandato del Código Único Disciplinario en sus artículos 182 a 191 en el cual se determinan las razones específicas por las cuales se inicia esta actuación especial y desde luego estará entrelazado con nuestra Carta política, ya que todas aquellas conductas descritas en el artículo 278 de esta última serán las razones por las cuales dichas faltas serán de resorte del Procurador (Brito, 2006). 
Dentro de las mencionadas razones se encuentran infringir de manera directa la Constitución o la ley, el uso indebido del patrimonio público, obstaculizar una investigación, o ser negligente durante su proceso o en la verificación de las quejas o de los presuntos hechos irregulares (Código Único Disciplinario, 2002).

Así pues, si el Procurador evidencia una de estas razones podrá dar inicio a la práctica especial del proceso con atención a las normas generales del derecho disciplinario antes descritas, pero con unas diferencias muy marcadas, y que a nuestro pensar son en las que radican las faltas de garantías del procedimiento bajo estudio.

La primera de ellas es que al ser el procurador la máxima autoridad disciplinaria, este proceso será de única instancia, por lo cual su decisión quedará en firme sin contradicción alguna, mientras que en el proceso ordinario el fallo disciplinario admite la verificación de controversias e inconformidades por medio del recurso de apelación (Brito, 2006).

Entonces, un servidor público electo por voto popular que es sancionado por este procedimiento especial no podrá interponer recurso alguno contra la decisión desfavorable la cual si versa sobre su destitución convergerá en una violación directa de su derecho a ser elegido ya que continuará apartado de sus funciones hasta tanto pueda iniciar la vía judicial ante lo contencioso administrativo, momento para el cual ya se habrán violado los derechos a elegir de los cientos de ciudadanos que votaron por dicho candidato y que esperan ver reflejado su poder de elección en un Estado democrático como el nuestro.

El procedimiento especial desarrollado por el procurador estará marcado por una tendencia a darle celeridad a la actuación, pero al mismo tiempo deja de lado el meticuloso cuidado que debe tenerse a la hora de realizarse el análisis probatorio y a dar cabida en forma pertinente a la contradicción. En el método desarrollado por el Procurador se cita al investigado a una audiencia en la cual se surten varias de las etapas que se llevan a cabo en la etapa preliminar, en la investigación, en el desarrollo de las pruebas e inclusive en el pliego de cargos.

En dicha audiencia se le informarán los hechos motivos de citación, las presuntas faltas realizadas, las pruebas recaudadas así como las solicitadas y su fecha y hora de 
realización. El investigado podrá aportar en esta audiencia las pruebas que tenga en su poder (Brito, 2006).

Aquí es donde se evidencia una de las más grandes posibilidades de violación a las garantías constitucionales y supralegales ya que de cumplirse con unos requisitos específicos podrá de forma sustentada ordenarse la suspensión del funcionario. Es aquí donde damos la cabida al Ministerio Público para que sin ser juez de la República retire a un servidor público de sus funciones.

La citación a la audiencia deberá hacerse por notificación personal y tendrá la misma relevancia que en el procedimiento ordinario, solo que, en esta actuación luego de notificada la citación se realizará la audiencia entre 10 y 15 días; tiempo durante el cual las partes podrán consultar el expediente en la Secretaría (Código Único Disciplinario, 2002).

Luego de la realización de las pruebas se procederá con los alegatos de conclusión; de no presentarse alegatos el expediente ingresará al despacho para proferir el fallo pertinente, al cual solo le procede el recurso de reposición (Bitro, 2006).

\section{Normas, TRATADOS Y CONCEPTOS DE LA CORTE INTERAMERICANA de Derechos Humanos que Van en Contravía de la Potestad DEL PROCURADOR GENERAL DE LA NACIÓN PARA DAR MUERTE POLÍTICA A UN FUNCIONARIO PÚBLICO ELECTO POR VOTO POPULAR}

En aras de cerrar la idea general, faltará por explicar de forma muy resumida los tratados, convenios de derecho internacional ratificados por Colombia y que por lo tanto hacen parte del bloque de constitucionalidad (Corte Constitucional, 2003).

Como ya lo he mencionado antes, esta parte del estudio cierra con precisión el análisis y permite empezar a vislumbrar las conclusiones y las presuntas posibilidades de mejora que podría tener el proceso disciplinario con el fin de asegurar un garantismo constitucional y convencional (Brito, 2006). 
En primer lugar, y como piedra filosofal de todo este desarrollo, será necesario mencionar el pacto internacional de derechos civiles y políticos de San José de Costa Rica adoptado y abierto para su adhesión por medio de la Resolución 220 A del 16 de diciembre del 66 y que entró en vigencia el 23 de marzo del 1966 (Naciones Unidas, Derechos Humanos, Oficina del Alto Comisionado, 2017).

Dicho pacto fue aceptado y ratificado por Colombia como Estado parte de las diferentes organizaciones internacionales que defienden y procuran la protección de derechos humanos. Este naciente proteccionismo arraigado se empieza a desarrollar y continúa en constante evolución desde los acuerdos realizados en Viena contra la esclavitud, pasando por la Carta de Derechos Humanos hasta los tratados de la Organización de Estados Americanos (Quiroga, 2009).

En concordancia con lo dispuesto anteriormente, es importante anotar que este nuevo sistema que algunos escritores han denominado la internacionalización de los derechos humanos y que inclusive han llegado a separarlos como siempre en procura de su máxima protección, los han individualizado como derechos de primera, segunda y tercera generación.

Ahora bien, entrando en materia debemos decir que el único medio de protección fehaciente, expedita y que de forma inmediata entra a velar por el correcto funcionamiento del procedimiento disciplinario sancionatorio, siempre con el respeto a los derechos humanos, será la Comisión Interamericana de Derechos Humanos y sus lineamentos de protección respecto de los servidores públicos electos por voto popular (Colegio24hrs, 2004).

Así pues, tendremos que profundizar en esta norma específica, sin dejar de lado jamás el bloque normativo, doctrinal e inseparable que forma su unión con los demás tratados que oscilan sobre derechos humanos, civiles, políticos y su protección. En este entendido, la Comisión ha dicho que la única manera viable para separar de un cargo a un funcionario electo por voto popular será la decisión de un juez de la República en la cual se hayan agotado las etapas procesales, se hayan asegurado los derechos a la contradicción y a una defensa técnica suficiente. 
$\mathrm{Al}$ estudiar nuestro procedimiento interno debe mencionarse nuevamente que no se tienen las garantías propias de un procedimiento de juzgamiento válido que cumpla con todos los requisitos mínimos para su desarrollo y que garantice el debido proceso, que no suplante decisiones de órganos de otras ramas del poder público y que asegure el garantismo constitucional y convencional de sus decisiones (Humberto, 1995).

De otro lado y guiados por la experiencia que se ha tenido en nuestro país, debe puntualizarse que el procedimiento disciplinario especial realizado por el procurador general, como ya se vio antes, no acata la protección de los derechos políticos ni del servidor público investigado, así como tampoco en el momento de su destitución e inhabilidad de los ciudadanos que votaron por él. Así mismo, los recursos que proceden contra dichas decisiones violatorias de los presupuestos expuestos por la Comisión no dan ninguna herramienta de protección inmediata.

Lo anterior es realmente preocupante, pero más lo es el hecho de que aun cuando dicho funcionario acuda a la jurisdicción internacional y que sea esta quien, al darse cuenta de la presunta violación de sus derechos a elegir y ser elegido, le solicite al Estado que garantice, por medio de una media cautelar de protección y aplicación inmediata, los derechos presuntamente violados, que el Estado haga caso omiso a dicha disposición y no le dé el procedimiento que se ordena. Así, al ser una orden vinculante de un organismo al cual Colombia se ha adherido, la medida cautelar es de obligatorio cumplimiento (Haideer, 2016).

Este tipo de actuaciones internas son realmente peligrosas y entran en contradicción directa con las disposiciones internas y los diferentes conceptos de múltiples doctrinantes del derecho internacional quienes han expuesto con suficiencia el poder vinculante que tiene una decisión de un órgano como la Comisión.

En un caso ya estudiado y mencionado en este artículo como lo fue la destitución e inhabilidad del alcalde de Bogotá de su momento, Sr. Gustavo Petro, por medio del procedimiento especial ordenado por el Código Único Disciplinario - ya explicado- - se ordenó su inhabilidad por un término de quince años; dicha decisión quedó firme posterior a resolver el tenue y poco funcional recurso de reposición (Alejandro A., 2014). 
El exalcalde acudió a la jurisdicción internacional, por medio de una solicitud de protección ante la Comisión Interamericana de Derechos Humanos, la cual por medio de la Resolución 347 generó la media cautelar en la cual solicitaba restituir al alcalde y permitirle continuar el mandato para el cual fue electo, dando prioridad a los derechos políticos de los electores y del funcionario (Alejandro A., 2014).

Hasta este punto el desarrollo no tiene irregularidades de importancia, sin embargo, posterior a la expedición de la medida cautelar el Estado colombiano hizo caso omiso y continúa con la decisión emitida por la Procuraduría General al punto de que el mismo presidente de la República nombró un alcalde provisional. Solo hasta después de pasados más de 45 días el exalcalde fue reubicado nuevamente en su cargo (Alejandro A., 2014).

Así las cosas, tendremos que replantear cuál es la importancia y el nivel de criterio y preferencia que tienen las decisiones expedidas por órganos internacionales, y cuál es el protocolo de aplicación interna, sus tiempos y procedimiento. Lo anterior ya que, como es evidente, estamos generando no solo una inestabilidad política interna, sino que quedamos en tela de juicio respecto de los demás países asociados a los órganos internacionales de protección.

Ahora bien, no se evidencia una amplia gama de ejemplos que se consideren violaciones a decisiones de organismos de derecho internacional que tengan que ver con derechos políticos de funcionarios electos por voto popular aparte del caso del exalcalde de Bogotá, Gustavo Petro.

Esto permite inferir que no es una constante este tipo de decisiones autoritarias y que carecen de fundamentos legales, y nos permite tomar medidas correctivas para que a futuro aquellas autoridades encargadas de que se acaten los ordenamientos internacionales hagan énfasis en la importancia de que esta protección se haga efectiva en forma inmediata cuando la media cautelar o el concepto vinculante de un organismo internacional lo prevea (Alejandro A, 2014). 


\section{Propuestas de mejora para la Relación de potestad y CRiterio PREFERENTE ENTRE LOS DERECHOS POLÍTICOS DE UN FUNCIONARIO ELECTO POR VOTO POPULAR Y LA POTESTAD DE DARLE MUERTE POLÍTICA POR PARTE DEL PROCURADOR GENERAL DE LA NACIÓN}

Atendiendo la temática en análisis, puede concluirse que el proceso disciplinario ha sido objeto de expansión; y esta expansión representa un reto para la dogmática jurídica (Huertas, 2016). En este sentido, llegamos entonces a la parte final de este estudio, para poder proponer posibles soluciones a corto, mediano y largo plazo, luego de haber explicado el estado actual en el que se encuentran las garantías de los procesos disciplinarios efectuados por la Procuraduría,

En primera instancia y a corto plazo proponemos que el procedimiento especial que lleva a cabo la Procuraduría General de la Nación se reglamente de forma más profunda y teniendo en cuenta las garantías constitucionales y convencionales que tiene un servidor público electo por voto popular.

Esto a través de la implementación de mecanismos que le permitan asegurar el desarrollo de un proceso garantista donde se sancionen aquellas actuaciones que reúnan los preceptos para ser consideradas como faltas graves y donde aquel servidor púbico que aproveche su cargo para obtener un enriquecimiento sin justa causa, o que desarrolle su trabajo de forma imprudente, negligente o poco eficaz, reciba su merecida sanción.

Pero que no se permita bajo ninguna circunstancia que la decisión verse sobre un proceso ineficiente, que le permita a un solo funcionario investigar, iniciar, continuar, acusar, y al mismo tiempo resolver la actuación que busca establecer si se han cometido presuntas faltas graves y/o gravísimas, y quien en dado momento puede incluso apartar al trabajador de su cargo.

Para alcanzar el mencionado fin será necesario que se establezcan con claridad los parámetros del procedimiento especial contra servidores públicos electos por voto popular, que al iniciar la etapa de investigación por parte de la Procuraduría el funcionario goce de las garantías constitucionales y convencionales mencionadas anteriormente. 
Para lograrlo de la manera más eficiente, proponemos que se reglamenten en forma independiente los procedimientos administrativos sancionatorios que oscilen sobre funcionarios que hayan sido electos por el sufragio, como una línea especial y de fundamental atención.

También, a mediano plazo, debe hacerse énfasis en que se le dé especial y preferente aplicación a las garantías constitucionales y a aquellos tratados, normas, convenios, acuerdos, pactos y demás decisiones de organismos internacionales en los cuales Colombia sea Estado parte, para que así se tenga la certeza del respeto por los derechos políticos.

Será fundamental, entonces, tener un criterio de unidad jurisprudencial, doctrinal y principalmente funcional para que las decisiones adoptadas por el Estado en este sentido estén armonizadas con los parámetros internacionales, entendiendo que las decisiones incluso consultivas de la Corte Interamericana de Derechos Humanos están enmarcadas por un proceso histórico de inconmensurables proporciones que abarca tanto la Corte Americana como los estados parte de la ozA.

Lo anterior para asegurar una estabilidad jurídica y democrática, para que los ciudadanos tengan la certeza de que el Estado social de derecho no es solamente un concepto que se repite ampliamente luego de la Carta Magna de 1991, sino, por el contrario, de que dichos dogmas guían el desarrollo de la función administrativa, más específicamente de su rama sancionatoria, como lo es el derecho disciplinario.

Lo que se requiere es un procedimiento en el cual se tenga la plena certeza de una investigación adecuada, que no permita abusar del poder, ni generar monopolio, de contratación o de cualquier otro tipo, y que al mismo tiempo de ejecutar una revisión minuciosa del trabajo desarrollado por el servidor público también se asegure un proceso totalmente garantista.

Una de las propuestas más importantes de mejora y que recae en uno de los principales problemas es que las etapas del procedimiento disciplinario contra servidores públicos electos por voto popular que lleve a cabo el procurador general de la Nación tenga el recurso de reposición y en subsidio el de apelación para que así se le permita dirimir en otra instancia y con un punto de vista diferente al del procurador la decisión desfavorable. 
Lo anterior de ninguna manera deja de lado la potestad preferente que tiene la Procuraduría ni mucho menos desvirtúa la fuerza de las decisiones del procurador general, o busca remover de su vital puesto este ministerio público, es solo que dicho procedimiento debe acoplarse a las nuevas tendencias políticas que están arraigadas ya desde hace varios años, debe actualizarse y su contenido requiere introducir como mínimo la protección eficiente a los derechos políticos protegidos por innumerables tratados.

Ahora bien, entre las propuestas a largo plazo estarán aquellas en las que el Estado colombiano entre a estudiar cuál es el grado de obligación que se tiene para con organismos internacionales como la Organización de Estados Americanos, la Corte Americana de Derechos Humanos, la Corte Interamericana de Derechos Humanos, etc. Lo anterior para que se tenga claridad sobre la incesante necesidad de acatar las directrices de este tipo de organismos.

Este punto revierte una importancia fundamental, ya que en este acápite no solo estamos hablando de la estabilidad jurídico-democrática interna, no; ahora hablamos de una seguridad y un respeto universalmente reconocido por los derechos políticos civiles de una persona.

Estamos entonces desconociendo todo un desarrollo histórico, político y social que ha dado como resultado las garantías políticas que transgredimos con este proceder, que va en sentido contrario a los valores sobre los cuales se fundamentan nuestras bases políticas y sociales y que debe modificarse en el sentido de acatar de forma inmediata la decisión proferida por un órgano internacional que busca ser garantista.

Así podremos tener la certeza de que aquellos servidores públicos electos por voto popular tendrán la vigilancia adecuada y en caso de cometerse una falta serán sancionados con el cumplimiento de los requisitos nacionales y extranjeros asegurando el debido proceso, la contradicción, la debida evaluación del material probatorio y la adecuada defensa, que darán como resultado un fallo ajustado al derecho.

Y, finalmente, si aún se contempla la inobservancia de algún fundamento superior, o la violación de algún derecho político protegido, que como última instancia con una debida sustanciación fáctica y jurídica se pueda solicitar que el fallo proferido por el 
procurador sea revisado con miras a que dicha decisión esté acorde a los lineamientos jurídicos nacionales e internacionales para que finalmente quede en firme.

Y que el procedimiento posterior a que sea modificado y reglado tenga el acompańamiento de la rama judicial para que así se tenga la plena certeza de que cualquier decisión que retire provisional o definitivamente a un servidor público de elección popular se desarrolle únicamente mediante sentencia de un juez de la República, como lo indican los pactos, derechos civiles y políticos ratificados.

\section{ConClusiones}

$\checkmark$ Por medio de la explicación detallada entre la relación potestativa y preferencial del procedimiento sancionatorio especial llevado a cabo por la Procuraduría y la primicia inexorable de la seguridad jurídica y democrática que da el derecho al voto en un país que desde el prólogo de su Constitución se anuncia como Estado social de derecho, podemos concluir que no hay una superioridad jerárquica entre las funciones asignadas al procurador contra el derecho al voto ya que ambas tienen una importancia primordial dentro de los diferentes procesos al interior del Estado y no podrá decirse que una pueda trasgredir los límites de la otra.

$\checkmark$ Se debe concluir que el procedimiento a cargo del procurador debe revisarse y modificarse positivamente con el fin de que de que este garantice que las decisiones que versen sobre funcionarios electos por voto popular serán tomadas con apoyo de la vía judicial y con respeto primordial al debido proceso.

$\checkmark$ Es necesario formar en derecho a los protagonistas del procedimiento sancionatorio para que haya respeto por las líneas doctrinales esbozadas por la Corte Interamericana de Derechos Humanos.

$\checkmark$ Se debe profundizar en el conocimiento y obligatoriedad de la aplicación de este tipo de decisiones a todos los funcionarios al servicio del Estado, tanto a aquellos que deciden, para que respeten estas normas, como sobre aquellos que se ven inmersos en una investigación, que no acatan estas directrices. 
$\checkmark \quad$ Es necesario que se incluyan mecanismos que le permitan al servidor investigado elevar aquellas decisiones desfavorables ante una autoridad que tenga la potestad de revisar y valorar la determinación tomada por el procurador. Lo anterior sin dejar de lado que este será la máxima autoridad en procesos disciplinarios desde que estos no recaigan en servidores electos por sufragio.

$\checkmark \quad$ La Corte Interamericana de Derechos Humanos es un órgano de decisión judicial dentro del Sistema Interamericano de Derechos Humanos, por tanto sus decisiones son coercitivas en todo sentido.

$\checkmark$ Se deben hacer efectivas las medidas cautelares dictadas por la Corte Interamericana de Derechos Humanos al tiempo que la autoridad encargada de ordenar su cumplimiento tenga conocimiento de esta. Puesto que la base de dicha determinación es evitar un daño irreparable, lo cual sucedería si no se toma medida alguna frente al caso elevado a consulta ante la Corte. Sin embargo, si el Estado parte no hace efectiva en el menor tiempo posible la medida de protección, no tendrá sentido.

$\checkmark \quad$ En la actualidad debe decirse que esta materia está muy poco explorada, ya que sus alcances e inconvenientes se vinieron a ver hace tan solo cinco años o menos, se debe enfatizar en ampliar el estudio del derecho comparado respecto de la protección de derechos políticos y el cumplimiento de decisiones de órganos internacionales.

\section{REFERENCIAS}

Alejandro, A. (2014) "Reflexiones e interrogantes del caso Gustavo Petro". Actualidad Jurídica Andina. Parlamento Andino. Bogotá, Colombia.

Arias, G. Y. (2011). Las medidas provisionales en la Corte Interamericana de Derechos Humanos: su contribución al derecho internacional de los derechos humanos. Santiago de Chile, Chile.: Universidad de Santiago de Chile. Recuperado de www.ebrary.com. sibulgem.unilibre.edu.co:2048

Código Único Disciplinario. (2002). Edición Legis. 
Código Único Disciplinario. Ley 734 de 2002. Recuperado de http://app.vlex.com.sibulgem.unilibre.edu.co:2048/\#WW/search/*/ley+734+de+2002/WW/vid/42856391.

Colegio24hs. (2004). Los derechos humanos. Buenos Aires, Argentina: Colegio24hs. Recuperado de http://www.ebrary.com.sibulgem.unilibre.edu.co:2048.

Convención Americana de Derechos Humanos. (2014). Córdoba, Argentina: El Cid Editor. Apuntes. Recuperado de http://www.ebrary.com.sibulgem.unilibre.edu.co:2048.

Corte Constitucional. Sentencia C-097 de 2003. M.P.: Manuel José Cepeda Espinosa.

Corte Interamericana de Derechos Humanos. (2014). Pacto Internacional de Derechos Civiles y Políticos. Córdoba, Argentina: El Cid Editor.

Corte Suprema de Justicia. Sentencia C-791 de 2014. M.P.: Humberto Antonio Sierra Porto.

Diario El País. (2015). Gestión de Alejandro Ordoñez. Recuperado de http://www.elpais. com.co/colombia/asi-fue-la-gestion-de-alejandro-ordonez-al-frente-de-la-procuraduria. html.

Ernesto, R. (2016). Las generaciones de los derechos humanos, 8. ${ }^{\circ}$ ed. Universidad Libre.

Fernando, B. (2006). Procedimiento disciplinario. Procuraduría General de la Nación. Bogotá: Editorial: Procuraduría General de la Nación

Gómez, A. (2016). El costo democrático de la democracia representativa. Revista Republicana, Núm. 22, enero-Junio de 2017, pp. 159-181. Recuperado de http://ojs.urepublicana.edu.co/index.php/revistarepublicana/article/view/381/338

Guevara, P. A. (2012). Los dictámenes consultivos de la Corte Intermamericana de Derechos Humanos. Interpretación constitucional y Convencional. Barcelona, España: J.M. Bosch Edit. Recuperado dewww.ebrary.com.sibulgem.unilibre.edu.co:2048.

Haideer, M. (2016). Diálogo judicial interamericano. Ediciones Nueva Jurídica.

Huertas, O. (2016) Entre la minimización y la expansión del derecho penal: la presencia de Beccaria en el debate contemporáneo. Revista IUSTA, N.o 44, enero-junio de 2016, pp. 41-59. Recuperado de http://revistas.usta.edu.co/index.php/iusta/article/ view/3075/2941

Humberto, Q. (1995). Los derechos humanos y su defensa ante la justicia. Temis. 
Legis. (2015). Constitución Política de Colombia. 33 edición.

Luis, V. (2007). La Ciencia Política desde el Derecho. Revista Derecho de Estado, N. 20. (Pp 45-78)

Miguel, A. (2009). Los órganos garantes de la autonomía política: defensa institucional y protección de los derechos: los casos de Italia, Alemania y España. Recuperado de http:// www.ebrary.com.sibulgem.unilibre.edu.co:2048. Consultada el día 12 de junio de 2017.

Naciones Unidas, Derechos Humanos, Oficina del Alto Comisionado. (2017). Pacto Internacional de Derechos Civiles y Políticos. Recuperado de http://www.ohchr.org/SP/ ProfessionalInterest/Pages/CCPR.aspx.

Nieves, M. (2016). Seguridad ciudadana y los sistemas de videovigilancia. Límites, garantías y regulación. Revista IUSTA, 45, julio-diciembre de 2016, pp. 129-163. Recuperado de http://revistas.usta.edu.co/index.php/iusta/article/view/3294/3104

Periódico El Tiempo (13 de enero de 2014). Las tres faltas por las que el procurador destituyó a Petro. Recuperado de www.eltiempo.com/archivo/documento/CMS-13356329

Periódico El Tiempo (3 de mayo de 2012). Procuraduría confirma destitución e inhabilidad de Alfonso Salazar. Recuperado de www.eltiempo.com/archivo/documento/ CMS-11708521.

Periódico El Tiempo (7 de marzo de 2014). Los argumentos del magistrado que votó a favor de las tutelas de Petro. Recuperado de www.eltiempo.com/archivo/documento/ CMS-13613418.

Procuraduría General de la Nación. (2017). Objetivos y funciones en página oficial de la Procuraduría General. Recuperado de https://www.procuraduria.gov.co/portal/Objetivos$\mathrm{y}$-funciones.page.

Quiroga, L. A. (2009). Relaciones entre el derecho internacional y el derecho interno: nuevas perspectivas doctrinales y jurisprudenciales en el ámbito americano. Santiago de Chile, Chile: Red Estudios Constitucionales. Recuperado de http://www.ebrary.com.sibulgem. unilibre.edu.co:2048

Rodríguez, J. (2017). Presidencia imperial y desequilibrio de poderes en Colombia. Revista Verba Iuris, No. 37, enero-junio 2017, pp. 79-89. Recuperado de http://www.unilibre. edu.co/verbaiuris/37/presidencia-imperial.pdf 
Romero, G. (2017). Libertad vs. populismo punitivo: ¿deben respetarse los derechos humanos en el proceso penal? A propósito de la nueva declaratoria de estado de cosas inconstitucionales para el sistema penitenciario y carcelario colombiano. Revista Via Inveniendi et iudicandi, 12(1), enero-junio 2017, pp. 89-117. Documento extraído el 5 de febrero de 2017 de http://revistas.usantotomas.edu.co/index.php/viei/article/view/3561/3449

Vacas, F. F. (2011). El reconocimiento del derecho al sufragio de los extranjeros en Espańa, un análisis desde el derecho internacional. Madrid. Recuperado de www.ebrary.com. sibulgem.unilibre.edu.co:2048. 